\title{
Pendidikan Kesehatan Dalam Upaya Pencegahan Kanker Serviks Pada Wanita Usia Subur
}

\author{
Vio Nita*1, Novi Indrayani ${ }^{2}$ \\ 1,2Program Studi S-1 Gizi, Fakultas Ilmu Kesehatan, Universitas Respati Yogyakarta \\ Email : vyoo7392@gmail.com*1,novi.indrayani.22@gmail.com²
}

\begin{abstract}
In Indonesia, cervical cancer (cervical cancer) is the second most common cancer among women after breast cancer. Some factors causing cervical cancer are late detection by women due to lack of knowledge about cervical cancer, for example to maintain the cleanliness of the female area (vagina) is very important especially for women. The purpose of this study was to determine the knowledge of Pre and Post health education in efforts to prevent cervical cancer in women of childbearing age in Ringinsari Bokoharjo Hamlet Prambanan Sleman Yogyakarta. The method used is quasi experiment with the "One Groups Pretest-Posttest Design" approach. Samples were 55 people, with accidental sampling technique. The results were that most (45.71\%) of pre-test knowledge of cervical cancer were in the poor category and after counseling the majority $(71.43 \%)$ were in the good category. Known p_value 0,000 <0.05, there are differences in knowledge about pre and post cervical cancer given health education.
\end{abstract}

Keywords: health education, cervical cancer, women

\begin{abstract}
Abstrak
Di Indonesia kanker serviks (kanker leher rahim) merupakan kanker kedua paling banyak diderita wanita setelah kanker payudara. Beberapa faktor mengakibatkan terjadinya kanker serviks adalah terlambatnya deteksi dini yang dilakukan oleh wanita karena kurangnya pengetahuan tentang kanker serviks, misalnya untuk menjaga kebersihan daerah kewanitaan (vagina) sangatlah penting dilakukan khususnya untuk wanita. Tujuan penelitian ini untuk mengetahui pengetahuan Pre dan Post pendidikan kesehatan dalam upaya pencegahan kanker serviks pada wanita usia subur Di Dusun Ringinsari Bokoharjo Prambanan Sleman Yogyakarta. Metode yang digunakan quasi eksperiment dengan pendekatan "One Groups Pretest-Posttest Design". Sampel berjumlah 55 orang, dengan teknik accidental sampling. Hasilnya sebagian besar (45,71\%) pre test pengetahuan kanker serviks dalam kategori kurang dan setelah diberi penyuluhan sebagian besar $(71,43 \%)$ dalam kategori baik. Diketahui p_value 0,000 <0,05, ada perbedaan pengetahuan tentang kanker serviks pre dan post diberi pendidikan kesehatan.
\end{abstract}

Kata Kunci : pendidikan kesehatan, kanker serviks, wanita

\section{PENDAHULUAN}

Angka kejadian penyakit kanker di Indonesia (136.2/100.000 penduduk) berada pada urutan 8 di Asia Tenggara, sedangkan di Asia urutan ke 23. Angka kejadian tertinggi di Indonesia untuk laki laki adalah kanker paru yaitu sebesar 19,4 per 100.000 penduduk dengan rata-rata kematian 10,9 per 100.000 penduduk, yang diikuti dengan kanker hati sebesar 12,4 per 100.000 penduduk dengan rata-rata kematian 7,6 per 100.000 penduduk. Sedangkan angka kejadian untuk perempuan yang tertinggi adalah kanker payudara yaitu sebesar 42,1 per 100.000 penduduk dengan rata-rata kematian 17 per 100.000 penduduk yang diikuti kanker leher rahim sebesar 23,4 per 100.000 penduduk dengan rata-rata kematian 13,9 per 100.000 penduduk.

Berdasarkan data Riskesdas, prevalensi tumor/kanker di Indonesia menunjukkan adanya peningkatan dari 1,4 per 1000 penduduk di tahun 2013 menjadi 1,79 per 1000 penduduk pada tahun 2018. Prevalensi kanker tertinggi adalah di provinsi DI Yogyakarta 4,86 per 1000 penduduk, diikuti Sumatera Barat 2,47 79 per 1000 penduduk dan Gorontalo 2,44 per 1000 penduduk [1].

Kanker serviks (kanker leher rahim) merupakan kanker kedua di dunia yang paling banyak diderita wanita setelah kanker payudara terutama di Negara Berkembang seperti 
Indonesia. IARC (International Agency For Research On Cancer) pada tahun 2012 menyebutkan prevalensi kejadian kanker payudara sebesar 40 per 100.000 wanita dan kanker leher rahim / serviks sebesar 26 per 100.000 wanita. Meningkatnya jumlah kasus baru kanker serviks di Indonesia pada setiap tahunnya ini dapat menjadi ancaman besar bagi dunia kesehatan, karena mayoritas penderitanya baru terdeteksi dan datang pada stadim lanjut. Padahal kanker serviks dapat dicegah dan terdeteksi lebih awal jika wanita usia subur mempunyai pengetahuan yang baik dan kesadaran melakukan deteksi dini [2].

Permasalahan kesehatan reproduksi yang ditemukan oleh penulis di Dusun Ringinsari Bokoharjo Prambanan Sleman Daerah Istimewa Yogyakarta adalah faktor yang membuat telambatnya deteksi dini yang dilakukan oleh wanita karena kurangnya pengetahuan tentang kanker serviks, misalnya untuk menjaga kebersihan daerah kewanitaan (vagina) sangatlah penting dilakukan khususnya untuk wanita dan bagaimana cara mendeteksi dini agar wanita tidak terkena kanker servik. Berdasarkan hasil wawancara dengan beberapa wanita didapatkan hasil ada beberapa wanita yang mengatakan tidak tahu informasi tentang kanker serviks yang diantaranya bagaimana pemeriksaannya dan dimana harus memeriksakannya. Disinilah pentingnya peran tenaga kesehatan untuk melakukan pendidikan kesehatan terkait deteksi dini kanker serviks kepada masyarakat.

Pengetahuan dan kesadaran masyarakat terutama wanita terhadap kesehatan reproduksinya dinilai masih kurang. Selama ini penyuluhan kesehatan juga dinilai masih kurang untuk masyarakat yang tinggal di pedesaan. Pendidikan kesehatan merupakan metode yang baik untuk memberikan informasi kesehatan reproduksinya kepada masyarakat khususnya wanita, tentang kanker serviks dan cara mendeteksi dini kanker serviks sehingga dapat menurunkan angka kematian.

\section{METODOLOGI}

Desain penelitian ini adalah quasi-eksperiment yaitu suatu penelitian dengan melakukan kegiatan percobaan (eksperiment) yang bertujuan untuk mengetahui gejala dan pengaruh yang timbul sebagai akibat dari adanya perlakuan tertentu [3]. Jenis rancangan "One Groups PretestPosttest Design" yaitu variabel diukur/diobservasi terlebih dahulu sebelum diberikan perlakuan (pre-test) setelah itu dilakukan perlakuan dan setelah perlakuan dilakukan pengukuran/obeservasi (post-test). Populasi penelitian ini adalah wanita usia subur di Dusun Ringinsari, Bokoharjo, Prambanan, Sleman, Yogyakarta. Pengambilan sampel pada penelitian ini menggunakan teknik sampling accidental sampling_yaitu sampel diambil secara kebetulan yang bertemu dengan peneliti dan cocok sebagai sumber data, sebanyak 55 wanita usia subur di Dusun Ringinsari, Bokoharjo, Prambanan, Sleman, Yogyakarta. Pengambilan data menggunakan kuesioner yang diberikan kepada wanita usia subur tersebut dan analisa data menggunakan uji paired t-test.

\section{HASIL DAN PEMBAHASAN}

Karakteristik Responden

Tabel 1. Umur Responden

\begin{tabular}{ccc}
\hline Umur & $\mathrm{N}$ & $(\%)$ \\
\hline $20-35$ tahun & 34 & 61,82 \\
$>35$ tahun & 21 & 38,18 \\
\hline Total & 55 & 100
\end{tabular}

Tabel 1 menunjukkan mayoritas responden umur 20-35 tahun sebanyak 34 orang (61,82\%) dan usia $>35$ tahun sebanyak 21 orang $(38,18 \%)$ 
Tabel 2. Pendidikan Responden

\begin{tabular}{ccc}
\hline Pendidikan & $\mathrm{N}$ & $(\%)$ \\
\hline Dasar & 11 & 20 \\
Menengah & 25 & 45,45 \\
Tinggi & 19 & 34,55 \\
\hline Total & 55 & 100 \\
\hline
\end{tabular}

Tabel 2 menunjukkan mayoritas responden mempunyai pendidikan menengah sebanyak 25 orang (45,45\%), berpendidikan dasar 11 orang 20\%) dan berpendidikan tinggi 19 respronden $(34,55 \%)$.

Tabel 3. Pekerjaan Responden

\begin{tabular}{ccc}
\hline Pekerjaan & N & $(\%)$ \\
\hline IRT & 21 & 38,18 \\
Karyawan Swasta & 15 & 27,27 \\
Wiraswasta & 19 & 34,55 \\
\hline Total & 55 & 100 \\
\hline
\end{tabular}

Tabel 3 menunjukkan mayoritas responden mempunyai pekerjaan sebagai ibu rumah tangga sebanyak 21 orang $(37,18 \%)$, karyawan swasta sebanyak 15 orang $(27,27 \%)$ dan wiraswasta 19 respronden $(34,55 \%)$.

Tabel 4. Tingkat Pengetahuan Sebelum Dilakukan Pendidikan Kesehatan Tentang Kanker Serviks

\begin{tabular}{ccc}
\hline Pengetahuan & N & $(\%)$ \\
\hline Baik & 9 & 16,36 \\
Cukup & 18 & 32,73 \\
Kurang & 28 & 50,91 \\
\hline Total & 55 & 100 \\
\hline
\end{tabular}

Diketahui sebagian besar pengetahuan sebelum dilakukan penyuluhan terkait dengan kanker serviks yaitu sebagian besar 50,91\% dalam kategori kurang.

Tabel 5. Tingkat Pengetahuan Setelah Dilakukan Penyuluhan Kesehatan Tentang Kanker Serviks

\begin{tabular}{ccc}
\hline Pengetahuan & $\mathrm{N}$ & $(\%)$ \\
\hline Baik & 33 & 60 \\
Cukup & 17 & 30,91 \\
Kurang & 5 & 9,09 \\
\hline Total & 55 & 100 \\
\hline
\end{tabular}

Berdasarkan tabel di atas diketahui bahwa sebagian besar $60 \%$ pengetahuan ibu setelah diberi penyuluhan tentang kanker serviks yaitu dalam kategori baik.

Tabel 6. Perbedaan Tingkat Pengetahuan Pre dan Post Test dilakukan Pendidikan Kesehatan Tentang Kanker Serviks

\begin{tabular}{ccc}
\hline Pengetahuan & $\mathrm{N}$ & $p$-value \\
\hline Positif Ranks & 55 & \\
Negatif Ranks & 0 & 0,000 \\
Ties & 0 & \\
\hline Total & 55 & \\
\hline
\end{tabular}


Hasil dari analisis yang telah dilakukan dari 55 responden diketahui bahwa 55 orang responden mengalami peningkatan pengetahuan, tidak ada responden yang mengalami penurunan pengetahuan dan tidak ada nilai yang sama antara pre test dan post test. Diketahui nilai $p$-value 0,000 $<0,05$ yang berarti ada perbedaan antara pengetahuan tentang kanker serviks sebelum dan sesudah diberi pendidikan kesehatan tentang kanker serviks.

Pendidikan kesehatan dalam upaya pencegahan kanker serviks sangatlah penting dikarenakan bahwa dengan semakin banyak seseorang mengetahui informasi atau pengetahuan tentang kanker serviks, maka semakin banyak pula para wanita usia subur khususnya dapat melakukan pemeriksaan secara dini untuk mencegah adanya keterlambatan dalam penanganan.

Diketahui hasil analisis pre dan post test didapatkan nilai signifikansi 0,000 yang berarti bahwa ada perbedaan antara pengetahuan sebelum dan setelah pendidikan kesehatan tentang kanker serviks. Pendidikan kesehatan merupakan proses yang mencakup dimensi dan kegiatankegiatan intelektual, psikologi, dan sosial yang diperlukan untuk meningkatkan kemampuan individu dalam mengambil keputusan secara sadar dan yang mempengaruhi kesejahteraan diri, keluarga, dan masyarakat. Pengetahuan sendiri adalah hasil "tahu"dan ini terjadi setelah orang mengadakan penginderaaan terhadap suatu obyek tertentu [6]. Banyak pengetahuan tentang deteksi dini kanker serviks, ibu menjadi banyak tahu tentang pentingnya pemeriksaan kanker serviks. Wanita yang tidak melakukan pemeriksaan kanker serviks dipengaruhi oleh beberapa faktor penyebab antara lain : faktor pengetahuan, faktor pendidikan, faktor usia dan faktor ekonomi.

Namun diketahui hal ini tidak cukup untuk mengubah suatu perilaku dikarenakan banyak faktor yang lainnya. Menurut Lawrence Green dalam Notoatmodjo (2010) terdapat faktor pendorong (predisposing faktors) merupakan faktor yang mempermudah atau mempredisposisi terjadinya perilaku seseorang, antara lain pengetahuan, sikap, keyakinan, kepercayaan, nilai-nilai, tradisi, dan sebagainya. Faktor pemungkin (enabling factors) merupakan faktor yang memungkinkan atau memfasilitasi perilaku atau tindakan. Faktor pemungkin maksudnya adalah sarana dan prasarana atau fasilitas untuk terjadinya perilaku kesehatan, misalnya: Puskesmas, Posyandu, Rumah Sakit, tempat pembuangan air, tempat pembuangan sampah, tempat olah raga, makanan bergizi, uang dan sebagainya. Faktor penguat (reinforcing factors) merupakan faktor yang mendorong atau memperkuat terjadinya perilaku.

Dalam hal ini, pengabdian kepada masyarakat dapat berjalan dengan lancar dan responden bisa memahami pendidikan kesehatan tentang upaya pencegahan kanker serviks dengan membagikan beberapa kuesioner. Responden yang telah diberikan pendidikan kesehatan tentang upaya pencegahan kanker serviks akan berbeda dengan responden yang sebelumnya belum diberikan pendidikan kesehatan dan dengan adanya pendidikan kesehatan yang seperti ini responden juga antusias untuk bisa mendeteksi dini kanker serviks dalam upaya pencegahan kanker serviks. Informasi terkait kanker serviks juga sangat penting agar responden (wanita) dapat memberikan informasi kepada keluarga, teman dan saudara agar bisa mencegah kanker serviks ini.

\section{KESIMPULAN}

Pengetahuan reponden sebelum diberi pendidikan kesehatan tentang kanker serviks dalam kategori kurang $(50,91 \%)$, sedangkan pengetahuan reponden sesudah diberi pendidikan kesehatan tentang kanker serviks dalam kategori baik (60\%). Diketahui nilai $p$-value 0,000<0,05 yang berarti ada perbedaan antara pengetahuan tentang kanker serviks sebelum dan sesudah diberi pendidikan kesehatan tentang kanker serviks. Pengetahuan yang baik harusnya sejalan dengan perilaku yang baik yaitu melakukan pemeriksaan kanker serviks secara rutin. Responden dalam hal ini juga akan menerapkan deteksi dini dalam upaya pencegahan kanker serviks.

\section{UCAPAN TERIMA KASIH}

Pengabdi mengucapkan terima kasih kepada Universitas Respati Yogyakarta yang telah memberikan dukungan baik moral maupun financial serta Dusun Ringinsari Bokoharjo 
Prambanan Sleman Daerah Istimewa Yogyakarta yang telah memberikan ijin terhadap kegiatan pengabdian kepada masyarakat ini.

\section{DAFTAR PUSTAKA}

Kementerian Kesehatan Indonesia. (2019). Profil Kesehatan Indonesia Tahun 2016. Jakarta : Kemenkes Indonesia

IARC (International Agency For Research On Cancer). (2012). Estimated Cancer Incidence, Mortality and Prevalence Wordwide in 2012. from http://globocan.iarc.fr/Default.aspx,

Arifin Zainal. (2014). Penelitian Pendidikan. Bandung : Remaja Rosdakarya

Sugiyono, (2012). Statistik Untuk Penelitian. Bandung : Alfabeta

Depkes, (2018). Riset Kesehatan Dasar (Riskesdas). Jakarta : Kemenkes

Dewi, M dan Wawan, A. (2010). Teori dan pengukuran pengetahuan, sikap, dan perilaku manusia. Yogyakarta: Nuha Medika

Kumalasari Dewi, Rahmatika Rina, Fitriana Titi Sahidah. (2019). Pendekatan Theraplay Untuk Meningkatkan Pengetahuan dan Keterampilan Bermain dengan Anak Penyandang Kanker. Dinamisia : Jurnal Pengabdian Masyarakat, Vol.3 No.1

Mardiana, Dasuki Djaswadi, Pradjatmo Heru. (2015). Pengetahuan dan Keterampilan Bidan Untuk Skrining Kanker Serviks Dengan Metode Inspeksi Visual Asam Asetat (IVA) Di Kalimantan Barat. Jurnal Kesehatan Reproduksi : Vo.2 No.1

Novel S. Sinta, dkk. (2010). Kanker Serviks dan Infeksi Human Pappilomavirus (HPV). Jakarta : Javamedia Network

Pebriana Marlinda, Trio Saputra, Wasiah Sufi. (2017). Sosialisasi Pemberian Air Susu Ibu (ASI) Di Kelurahan Sidomulyo Barat Kecamatan Tampan Kota Pekanbaru. Dinamisia : Jurnal Pengabdian Masyarakat, Vol.1 No.1

Sukmawati, Mamuroh Lilis, Nurhakim Furqon. (2020). Pendidikan Kesehatan dan Pelaksanaan Iva Test pada Wanita Usia Subur. Medika Karya Kesehatan : Vol.3 No.1 